\title{
Morphological studies and meiotic chromosome analysis of Epimedium elatum (Morr \& Decne)- Rare endemic medicinal plant of the Northwestern Himalayas in India
}

\author{
Sajad Ahmad Lone ${ }^{1,3}$, Qazi Pervaiz Hassan ${ }^{1,3 *}$, Suphla Gupta ${ }^{2,3}$, Saleem Mushatq ${ }^{1}$, \\ Phalisteen Sultan ${ }^{1,3}$, Yashbir Singh Bedi2,3
}

${ }^{1}$ Department of Biotechnology, CSIR-Indian Institute of Integrative Medicine, Srinagar, Jammu and Kashmir, India, ${ }^{2}$ Department of Plant Biotechnology, CSIR-Indian Institute of Integrative Medicine, Srinagar, Jammu and Kashmir, India, ${ }^{3}$ Academy of Scientific and Innovative Research (AcSIR), Anusandhan Bhawan, New Delhi, India

Received: 11-01-2017
Accepted: 30-01-2017
Published: 02-02-2017
*Address for
correspondence:
Qazi Parvaiz Hassan,
Department of
Biotechnology,
Indian Institute of
Integrative Medicine,
Srinagar - 190 005,
Jammu and Kashmir, India.
Tel.: +911/94/2431 255.
Fax: +911/94/2430 779.
E-mail: pervaizqazi@yahoo.
com
com

\begin{abstract}
Epimedium elatum (Berberidaceae) is a rare endemic medicinal herb of the Northwestern Himalayas in India. Recent ethnopharmacological reports have demonstrated its traditional medicinal use against various bonerelated diseases in the Kashmir Himalayas. It owes its pharmaceutical importance due to high concentration of flavonoid glycosides like Epimedin A, B, C and Icariin which are known mainly for aphrodisiac, antiosteoporosis, anticancer, antioxidant, antiaging, antifatigue, and antiviral activities. It is a neglected medicinal plant in the Northwestern Himalayan region and may fall in the list of endangered species due to continuous anthropogenic pressures in its native habitats. In this study, we investigated distributional and altitudinal range of this prized species from 20 diverse eco-geographical zones of Kashmir Himalayas for the first time. We also report here its diversity in morphological attributes both in wild and captive cultivation. The species has a very small population size in most of the surveyed habitats with no natural protection. Under cultivation it showed increased plant height $(63.09 \pm 4.9 \mathrm{~cm})$, more number of leaves $(95.53 \pm 11 \mathrm{~cm})$ and flowers $(160.76 \pm 20 \mathrm{~cm})$, indicating importance of high altitude medicinal garden for its immediate ex situ conservation. Further, the acetocarmine staining and squashing of young anthers confirmed it as a diploid species $(2 n=12)$ like other Epimedium species. Chromosome number and meiotic abnormalities are also reported for the first time in the species. Finally, constant anthropogenic pressures in the Northwestern Himalayas demand immediate in situ and ex situ conservation programs for E. elatum.
\end{abstract}

KEY WORDS: Accession, conservation, chromosomes, Epimedium elatum, Kashmir Himalayas

\section{INTRODUCTION}

Epimedium elatum (Berberidaceae) is a genus with more than 65 accepted species (The Plant List 2013). They are mostly perennial species with heart shaped leaves and majority of them have 4-parted "spider-like" flowers in spring season (Ma et al., 2011). They are distributed in North Temperate Zones in China, Japan, Korea, Europe and some African countries (Zhang et al., 2016). Medicinally, they are known as Herba Epimedii, a famous botanical supplement prepared from 5 Epimedium species, viz., Epimedium brevicornum, Epimedium sagittatum, Epimedium koreanum, Epimedium pubescens, and Epimedium wushanense
(Ma et al., 2011). Epimedin-A, Epimedin-B, Epimedin-C, and Icariin are the major chemical constituents in almost all Epimedium species (Chen et al., 2015). They are known to possess a number of pharmacological actions such as aphrodisiac (phosphodiesterase-5 inhibition), antiosteoporosis, antioxidation, antitumor, and antiaging activities (Ma et al., 2011).

E. elatum (Morren and Decne) is a sparsely branched, low growing, perennial, and deciduous medicinal herb, which reaches a height of about $100 \mathrm{~cm}$ in shady habitats in Kashmir Himalayas (www.srgc.net). According to recent reports, E. elatum is the only medicinal species in 
Epimedium genus which is exclusively endemic to high altitude shady coniferous forests of the Northwestern Himalayas in India and Pakistan (www.gbif.org; Nasir and Ali 2005; Perveen and Qaiser 2010; Tantry et al., 2012; Naseer et al., 2015, Arief et al., 2015, 2016; Lone et al., 2016). It has several local common names such as Saul Sumbal, Chhal Kambli, and "mosquito herb" and its extract is sprayed as rodent and mosquito repellent in some Himalayan communities (Arief et al., 2015). Traditionally, E. elatum has been used to treat cold, cough, running nose, toothache, tooth-decay, diseases of bones and joints (Arief et al., 2015). Phytochemically, E. elatum contains high concentration of Epimedin A, Epimedin B, Epimedin C, Icariin, Icariside-Iand same has been confirmed by its recent bio prospection in Kashmir Himalayas (Sofi et al., 2014; Naseer et al., 2015; Arief et al., 2015, 2016).

Phenotypic plasticity in plants is defined as the ability of a single genotype to develop multiple phenotypes under different eco-edaphic environmental conditions (Palacio-Lopez et al., 2015). High altitude medicinal plants are known to show a significant phenotypic plasticity in the Northwestern Himalayas (Badola and Aitken 2003). Epimedium species too are known to show phenotypic plasticity both in wild and cultivated conditions (Quan et al., 2011; Xu et al., 2013b; Xu et al., 2014; Chen et al., 2015b; Pan and Guo 2016; Xuemei et al., 2016). It indicates the existence of different phenotypes and genotypes in Epimedium species under different environmental conditions. In our earlier study, we have reported its diversity at genetic, phytochemical, and biochemical level. It shows wide phenotypic plasticity according to the habitat conditions. Under open sunny conditions, it shows "dwarf habit" whereas in shady conditions, it shows robust growth with maximum herbage, favorable for the plant (Lone et al., 2016). However, several medicinal plants have also become threatened in the Northwestern Himalayas due to various anthropogenic threats (Tali et al., 2015). E. elatum too can become threatened in near future if timely conservation measures are not taken. In this regard, conserving germplasm of E. elatum was highly important. There is need to study this medicinal plant in detail from various botanical aspects such as phenotypic plasticity, local distributional, and altitudinal pattern in Kashmir Himalayas and basic chromosome number. These classical efforts will help to generate more research interests toward this neglected medicinal plant species in Kashmir Himalayas. This medicinal plant could be explored further for its nutraceutical and pharmacological properties in coming decades due to its high content of prenylated flavonoids.

\section{MATERIALS AND METHODS}

\section{Study Area}

This study was mainly done in the Kashmir Valley in the Northwestern Himalayan biogeographic zone, situated on the northern edge of India. It extends from $33^{\circ} .20^{\prime}$ and $34^{\circ} .54^{\prime} \mathrm{N}$ latitudes and from $73^{\circ} .55^{\prime}$ and $75^{\circ} .35^{\prime} \mathrm{E}$ longitudes covering an area of $15,948 \mathrm{~km}^{2}$. Topographically, it is a deep elliptical bowl-shaped valley surrounded by mountains of the Pir Panjal in the South and Southwest and by the Greater Himalayan range in the North and East (Tali et al., 2015). The areas surveyed included 20 eco-geographical zones from Pir Panjal ranges to Gurez valley of higher Himalayas in Kashmir, India (Table 1).

\section{Eco-geographical Survey and Diversity in Morphology}

An eco-geographic survey was undertaken within Kashmir Himalayan forests for determining the distributional and altitudinal range of E. elatum. Various floras (Singh and Kachroo., 1987; Sharma and Jamwal, 1998), herbarium records, research articles and internet research tools like Google scholar, Scopus, etc.) were consulted for working out its distribution in Kashmir Himalayas. The information collected was used to plan the time table and routes for field studies. The study area was thoroughly surveyed for ensuring collection of the required material. Several parameters such as altitude, latitude, longitude, including morphological parameters such as plant height $(\mathrm{cm})$, branch and leaf number, leaf length and breadth, petiole length, inflorescence length, flower length and breadth, etc., were recorded. Same measurements were done on randomly selected mature individuals from each accession. Depending on availability, suitable numbers of specimens were collected, and their field information was recorded under a specific collection number. The plant specimens were dried and preserved via standard taxonomic methods. They were identified and subsequently at Centre of Plant - Taxonomy, University of Kashmir and Janaki Ammal Herbarium (Figure 1), Indian Institute of Integrative Medicine, Jammu and Kashmir, India.

\section{Transplantation at Experimental Farms}

E. elatum with immature rhizome buds were sampled at random from mountain forests of Gulmarg $(2700 \mathrm{~m}$ ) and Aharbal $(2500 \mathrm{~m})$ during early winter. They were transplanted under shade at two experimental field stations atYarikhah (Tangmarg) and Sanatnagar (Srinagar), respectively. Forest mulch brought from wild was subsequently mixed with soil to mimic natural habitats during transplantation. Morphological measurements were made between 2013 and 2015. All parameters on 
Table 1: Accession numbers, geographic location, and habitat status of the 20 studied populations of Epimedium elatum in Kashmir Himalayas

\begin{tabular}{|c|c|c|c|c|c|c|c|c|}
\hline Accessions & Locality/District & Codes* & Vouch $^{1}$ & Vouch $^{2}$ & Alt.asl ${ }^{3}$ & Latitude & Longitude & Habitat status \\
\hline Gulmarg & Baramulla & $G L$ & 2094 & 22304 & 2725 & $34.02^{\circ}$ & $74.22^{\circ}$ & Nature reserve \\
\hline Babareshi & Tangmarg Baramulla & $\mathrm{BR}$ & 2099 & 22306 & 2694 & $34.03^{\circ}$ & $74.23^{\circ}$ & Nature reserve \\
\hline Drang & Tangmarg Baramulla & DR & 2105 & 22305 & 2301 & $33.55^{\circ}$ & $74.29^{\circ}$ & No protection \\
\hline Dangarpora & Sheeri Baramulla & $D G$ & 2103 & 22308 & 2592 & $34.05^{\circ}$ & $74.32^{\circ}$ & No protection \\
\hline Boniyar & Uri Baramulla & BY & 2107 & 22307 & 2148 & $34.15^{\circ}$ & $74.21^{\circ}$ & Nature reserve \\
\hline Yusmarg & Budgam & YS & 2101 & 22310 & 2383 & $33.49^{\circ}$ & $74.40^{\circ}$ & No protection \\
\hline Dodipathri & Budgam & $\mathrm{DP}$ & 2095 & 22309 & 2432 & $33.53^{\circ}$ & $74.34^{\circ}$ & Nature reserve \\
\hline Naranag & Kangan Ganderbal & NAR & 2102 & 22303 & 2272 & $34.21^{\circ}$ & $74.58^{\circ}$ & Nature reserve \\
\hline Gagangir & Kangan Ganderbal & $\mathrm{GG}$ & 2109 & 22314 & 2435 & $34.17^{\circ}$ & $75.12^{\circ}$ & No protection \\
\hline Dachigam & Harwan Srinagar & $\mathrm{DGM}$ & 2100 & 22312 & 2912 & $34.08^{\circ}$ & $75.02^{\circ}$ & Nature reserve \\
\hline Pahalgam & Anantnag & $P G M$ & 2093 & 22319 & 2206 & $34.00^{\circ}$ & $75.18^{\circ}$ & No protection \\
\hline Kokernag & Anantnag & KNG & 2092 & 22311 & 2343 & $33.34^{\circ}$ & $75.17^{\circ}$ & No protection \\
\hline Verinag & Anantnag & VNG & 2108 & 22320 & 1935 & $33.32^{\circ}$ & $75.14^{\circ}$ & Nature reserve \\
\hline Khillanmarg & Gulmarg Baramulla & KMG & 2104 & 22315 & 3133 & $34.02^{\circ}$ & $74.21^{\circ}$ & Nature reserve \\
\hline Chaknala & Gurez Bandipora & CNG & 2097 & 22316 & 2508 & $34.37^{\circ}$ & $74.51^{\circ}$ & No protection \\
\hline Sheikhpora & Tilayl Gurez Bandipora & $S P G$ & 2096 & 22317 & 2646 & $34.35^{\circ}$ & $74.59^{\circ}$ & No protection \\
\hline Kanzalwan & Gurez Bandipora & $K Z G$ & 2098 & 22318 & 2431 & $34.38^{\circ}$ & $74.42^{\circ}$ & Nature reserve \\
\hline Badwan & Gurez Bandipora & $B D G$ & 2106 & 22321 & 2521 & $33.39^{\circ}$ & $74.46^{\circ}$ & Nature reserve \\
\hline Hirpora & Shopian & $\mathrm{HP}$ & 2090 & 22322 & 1818 & $33.39^{\circ}$ & $74.57^{\circ}$ & No protection \\
\hline Aharbal & Kulgam & $A B$ & 2091 & 22313 & 2425 & $33.38^{\circ}$ & $74.74^{\circ}$ & Nature reserve \\
\hline
\end{tabular}

*Accession codes of Epimedium elatum. ${ }^{1,2}$ Voucher specimens deposited at Kashmir University Herbarium (Srinagar) and Janaki Ammal herbarium (IIIM Jammu). ${ }^{3}$ Altitude is given in meters above sea level

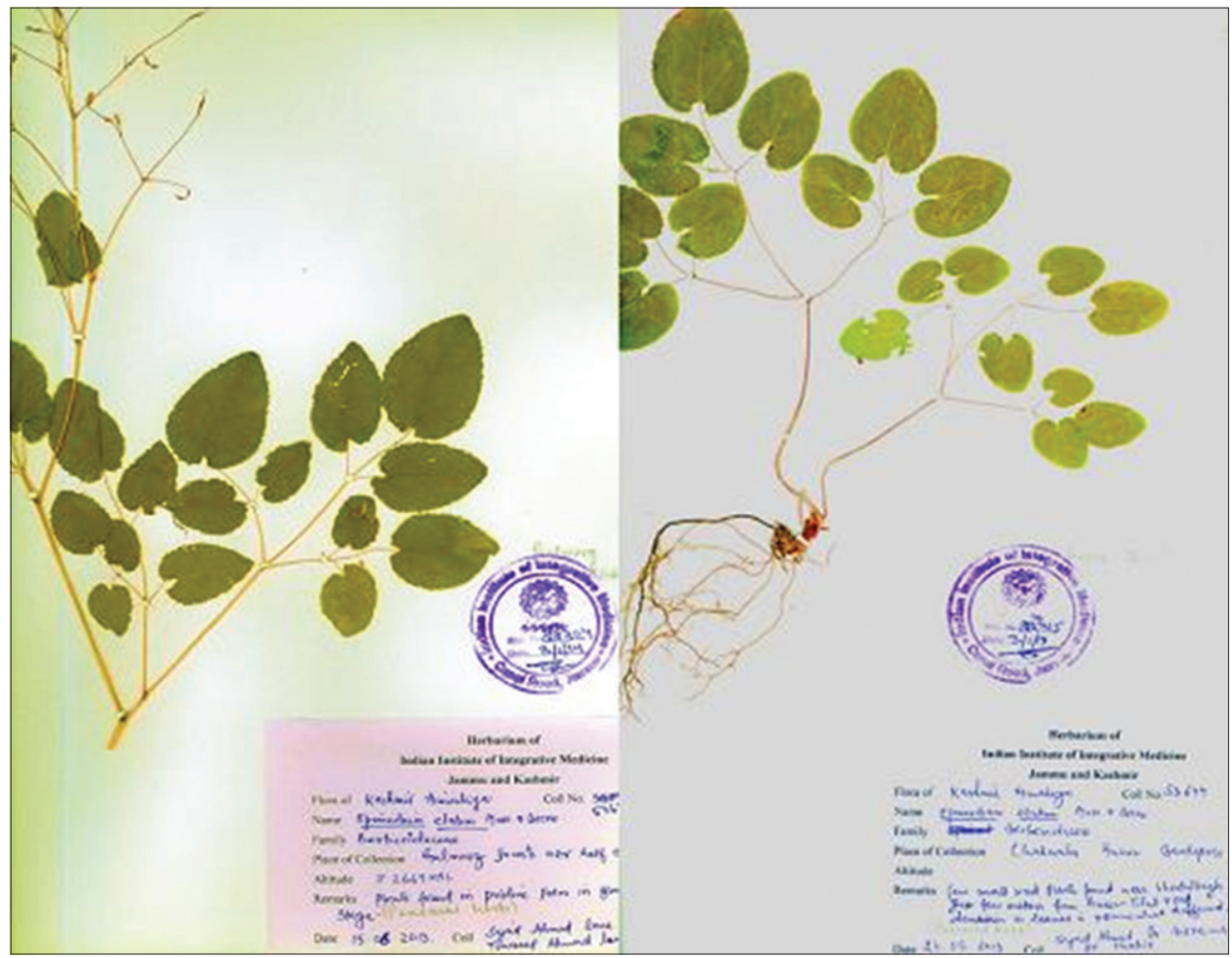

Figure 1: Taxonomic identification of Epimedium elatum with characteristic "three branches and nine leaved morphology"

morphology were statistically analyzed for mean and standard error.

\section{Meiotic Chromosome Analysis}

For meiotic studies, young and immature flower buds were collected randomly from wild eco-zones (Drang and Gulmarg) and also from plants cultivated at experimental field stations in months of April and May 2014. Plants having ideal buds were selected at different times of the day from early morning to ensure accuracy in getting perfect meiotic stages. They were fixed in freshly prepared Carnoy's fixative (ethanol/chloroform/ 
acetic acid $-6: 3: 1, \mathrm{v} / \mathrm{v} / \mathrm{v}$ ) for $24 \mathrm{~h}$, washed thrice with $70 \%$ ethanol to remove the fixative and stored at $4{ }^{\circ} \mathrm{C}$ until use. The meiotic studies were carried out on young flower buds using standard acetocarmine smear technique. For slide preparation the anthers were squashed in $1 \%$ acetocarmine and slides were studied for chromosome counts, and meiotic behavior in pollen mother cells (PMCs) at early prophase-I, diakinesis, metaphase-I (MI), anaphases-I/II (AI/II), telophases.

I/II (TI/II) and sporad stages, respectively. All meiotic phases were evaluated and abnormalities if any were recorded. The gametic chromosome number was determined in at least 10 PMCs at diakinesis from all four populations (two wild and two cultivated). In populations with abnormal meiotic course, a total of 30-50 PMCs were examined.

\section{Photomicrographs}

The PMCs with perfect stages (for chromosome counts, meiotic abnormalities, and sporads) were initially observed with light microscope and later under Carl Zeis Microscope supported by Labomed digital camera. Photomicrographs reported in this study were taken via $\times 100$ magnification lens using immersion oil for better resolution.

\section{RESULTS}

\section{Phenotypic Plasticity in Wild Habitats}

During exhaustive eco-geographical surveys, 20 accessions of this species were collected from Kashmir Himalayas,
India (Figure 2). Small population size and localized distribution in specific pockets reflect its critically rare status in Kashmir Himalayas. It showed wide phenotypic plasticity in all 20 accessions, collected from diverse eco-geographical zones. The highest plant height (100$110 \mathrm{~cm}$ ), more number of branches and leaves were found in Gulmarg, Verinag, Naranag, and Aharbal accessions while minimum values $(12-18 \mathrm{~cm})$ were recorded for Kokernag, Pahalgam, Yusmarg, and Gagangir accessions (Figure 3). Moreover, cool-moist environment, deep shade of bushes, thickets and shrubs was found to favor tall habit of this species in naturally protected habitats (Table 2), whereas open sunny environment was found to favor dwarf phenomenon, as reported by Quan et al. 2011 in Epimedium species. It is considered to be the tallest (4 feet) Epimedium species (www.srgc.net) and unique eco-edaphic environment of the Nor thwestern Himalayas could be the reason for this phenotype plasticity. This is the first report wherein the morphology and distribution of this species have been studies in diverse habitats in Kashmir valley, India.

\section{Morphological Variability under Cultivation}

E. elatum transplanted at two field stations were measured for diversity in their phenotypic plasticity. Plants at Yarikhah farm (Tangmarg) were better adapted as showed increased plant height $(63.09 \pm 4.9 \mathrm{~cm})$, maximum number of leaves $(95.53 \pm 11 \mathrm{~cm})$ and flowers $(160.76 \pm 20 \mathrm{~cm})$ per plant (Table 3). Because of the high relative light intensity at Srinagar farm, dwarf

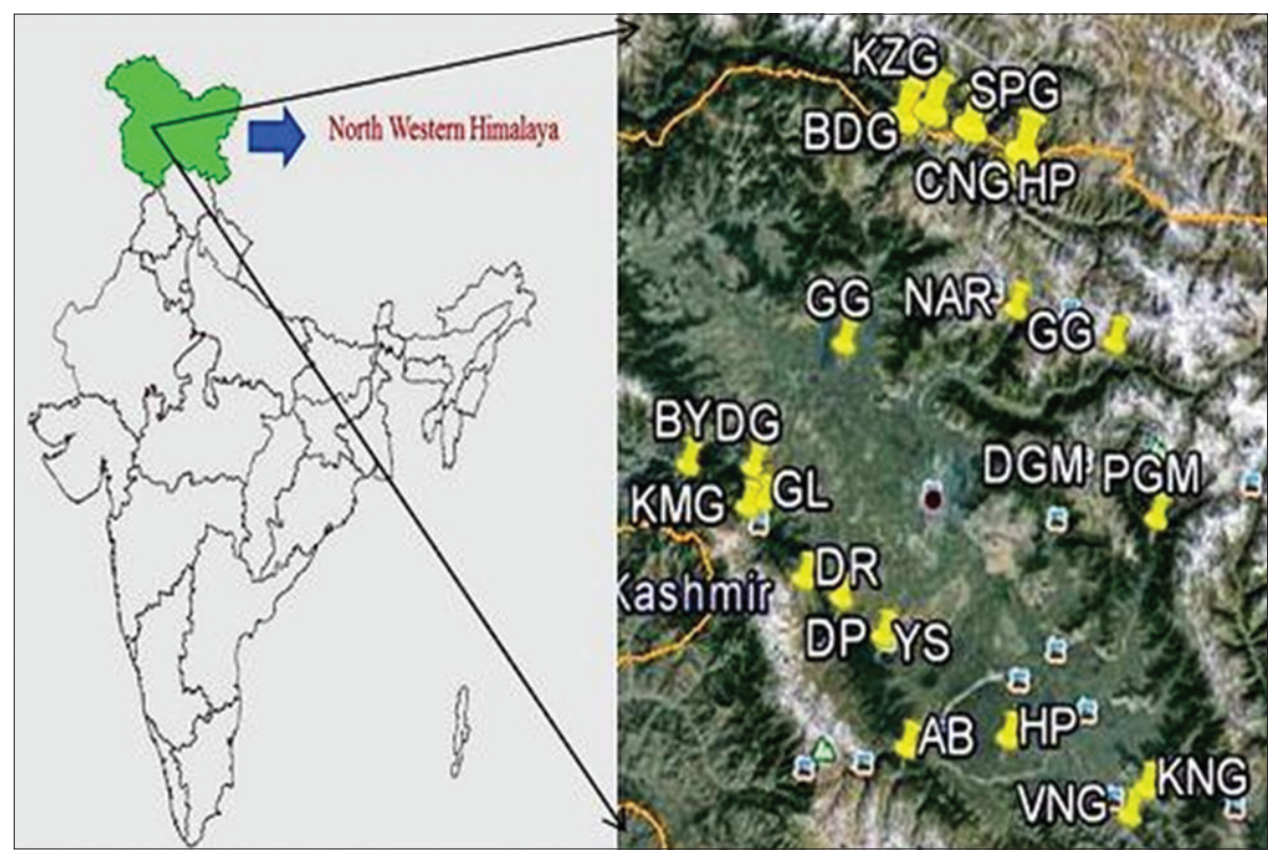

Figure 2: Geographical map showing the geographical distribution of 20 accessions of Epimedium elatum in Kashmir Himalaya, J \& K, India (Table 1 for accession codes) 
Table 2: Morphological comparison of different accessions of E. elatum recorded during eco-geographical surveys

\begin{tabular}{|c|c|c|c|c|c|c|c|c|c|}
\hline Acc $\operatorname{codes}^{\mathrm{a}}$ & $\begin{array}{c}\text { Plant } \\
\text { height }(\mathrm{cm})\end{array}$ & Branches/plant & Leaves/branch & $\begin{array}{c}\text { Petiole } \\
\text { length }(\mathrm{cm})\end{array}$ & $\begin{array}{c}\text { Leaf size }(\mathrm{cm}) \\
\text { L/B }\end{array}$ & Inflorescen. length $(\mathrm{cm})$ & $\begin{array}{c}\text { Flower size }(\mathrm{cm}) \\
\text { L/B }\end{array}$ & $\begin{array}{c}\text { Pod } \\
\text { length }(\mathrm{cm})\end{array}$ & Habit (Herb) \\
\hline GL & $62.2-110$ & $16-22$ & $18-54$ & $2.5-3.8$ & $4.5-7.0 / 4.0-4.8$ & $18-29$ & $0.9-1.0 / 0.8-1.0$ & $2.2-3.3$ & Tallest \\
\hline BR & $48-77$ & $12-18$ & $18-45$ & $1.9-2.6$ & $5.1-8.5 / 4.0-4.7$ & $11-21$ & $0.8-1.0 / 0.9-1.0$ & $1.8-2.9$ & Tall \\
\hline DR & $28-58$ & $6-12$ & $18-36$ & $1.5-3.0$ & $4.1-5.5 / 3.1-4.2$ & $9.0-12$ & 0.9-1.0/0.8-0.9 & $2.1-3.0$ & Medium \\
\hline DG & $32.1-48$ & $3-06$ & 12 & $1.1-1.3$ & $4.8-5.3 / 4.1-4.3$ & $12.1-16.1$ & $0.8-0.9 / 0.8-0.9$ & $1.9-2.0$ & Small \\
\hline BY & $49.2-101.2$ & $15-24$ & $18-36$ & $1.4-1.9$ & $5.1-6.4 / 4.0-4.7$ & $12-17$ & $0.8-0.9 / 0.7-1.0$ & $1.2-1.7$ & Tall \\
\hline YS & $20-39.2$ & $3-5$ & $9-11$ & $0.9-1.3$ & $2.4-4 \cdot 1 / 2 \cdot 0-2.8$ & 7.5-9.1 & $0.8-0.9 / 0.6-0.9$ & $1.1-1.9$ & Small \\
\hline DP & $42-86$ & $13-16$ & $18-36$ & $1.1-1.8$ & $5.0-6.6 / 4.0-6.3$ & $15-18.1$ & $0.8-0.9 / 0.8-0.9$ & $2.9-3.3$ & Tall \\
\hline NAR & $86.0-101.2$ & $16-20$ & $27-55$ & $2.1-2.9$ & $5.8-6.3 / 4.0-4.7$ & $19-26$ & NA & $2.0-2.3$ & Tallest \\
\hline GG & $18.1-42.1$ & 6 & $14-13$ & $0.9-1.2$ & $4.0-4.9 / 2.3-2.9$ & $12.1-16.1$ & $0.9-1.1 / 0.8-0.9$ & $1.9-2.0$ & Small \\
\hline DGM & $85.3-102.3$ & $13-29$ & $27-36$ & $1.3-1.5$ & 7.3-7.4/4.9-5.1 & $18.3-25$ & $0.8-1.0 / 0.9-1.0$ & $2.1-2.7$ & Tallest \\
\hline PGM & $18.1-42.8$ & $6-12$ & $9-12$ & $1.1-1.2$ & $4.2-5.6 / 2.9-3.8$ & $12.1-16.1$ & $0.8-0.9 / 0.8-0.9$ & $1.9-2.0$ & Small \\
\hline KNG & $12-23.4$ & $4-08$ & $12-16$ & 1.1 & $4.0-4.8 / 2.8-2.9$ & NA & NA & NA & Small \\
\hline VNG & $48-76$ & $16-17$ & $36-65$ & $1.0-1.4$ & $5.8-6.4 / 4.0-4.8$ & $9.8-16.1$ & $0.7-1.0 / 0.9-1.0$ & $1.9-2.9$ & Tall \\
\hline KMG & $21.1-29$ & 4 & $9-16$ & $1.1-1.3$ & $3.2-3.9 / 2.1-2.9$ & NA & NA & NA & Small \\
\hline$C N G$ & $28.1-50.2$ & $8-18$ & $16-36$ & $1.1-1.3$ & $3.2-5.6 / 2.3-2.9$ & NA & NA & $1.9-2.0$ & Small \\
\hline$S P G$ & 48.1-58.1 & $14-21$ & $27-36$ & $1.1-1.3$ & $4.7-5.2 / 3.1-3.8$ & NA & NA & NA & Medium \\
\hline$K Z G$ & $28.3-70.3$ & $13-19$ & $26-56$ & 1.1 & $4.0-5.2 / 3.1-3.5$ & NA & NA & NA & Medium \\
\hline$B D G$ & $78.8-100.1$ & $18-21$ & $18-63$ & $1.1-1.3$ & $5.1-5.7 / 4.1-4.8$ & NA & NA & NA & Tall \\
\hline HP & $15-25.3$ & $5-15$ & $9-12$ & $1.1-1.3$ & $4.1-4.2 / 2.2-2.4$ & NA & NA & NA & Small \\
\hline$A B$ & $95-110$ & $23-32$ & $45-95$ & $2.4-3.5$ & 5.8-8.2/5.8-6.1 & $29-39$ & $0.8-1 / 0.9-1.0$ & $3.1-3.9$ & Tallest \\
\hline
\end{tabular}

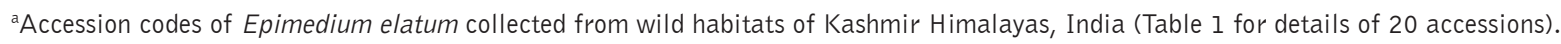

E. elatum: Epimedium elatum, NA: Not available
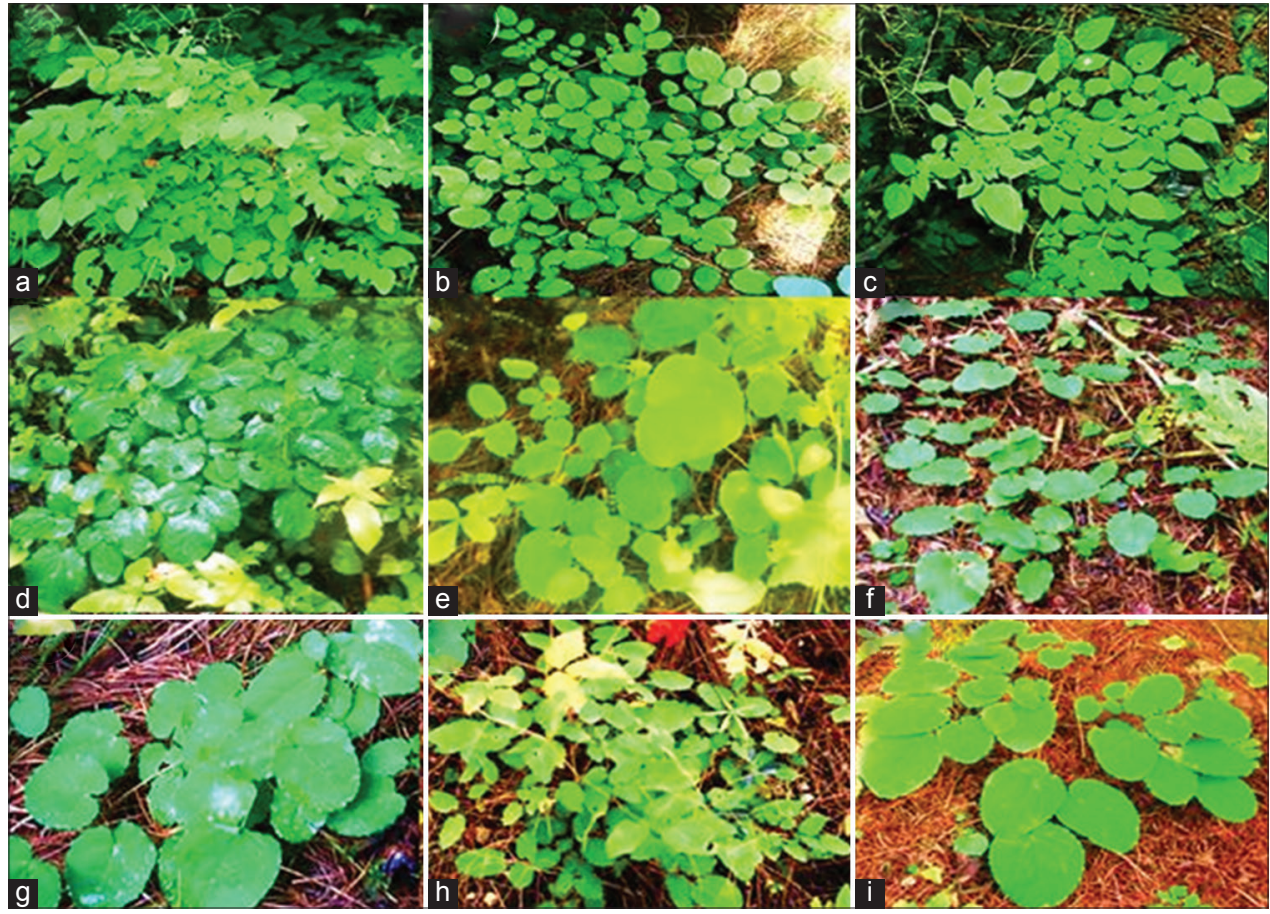

Figure 3: Representative populations of Epimedium elatum growing in wild (eco-geographical zones) habitats of Kashmir Himalayas in India. (a) Aharbal, (b) Verinag, (c) Naranag, (d) Gulmarg, (e) Boniyar, (f) Khillanmarg, (g) Pahalgam, (h) Sheikhpora, (i) Chaknala. Note the tall and small habit of the same plant species under different habitat conditions indicating phenotypic plasticity prevalent in this species

phenomenon occurred in E. elatum. This was observed in wild habitats where partial shade and sunny conditions were found to induce dwarfness in E. elatum. Similar observations were made previously in E. pubescens and $E$. wushanense, in both wild and cultivation (Quan et al., 2011). According to specimen examination, field investigation, and observations of material in cultivation, E. elatum is a small flowered taxon (Figure 4). The botanical description of this medicinal plant is given in Table 4. It prefers cool shady environment for acclimatization even at low altitude conditions. The phenology of the plant was recorded, and it was found to flower differently in wild and cultivated conditions. At low altitude habitats like Dachigam National Park $(1600 \mathrm{~m})$ it was observed to flower in the month of 


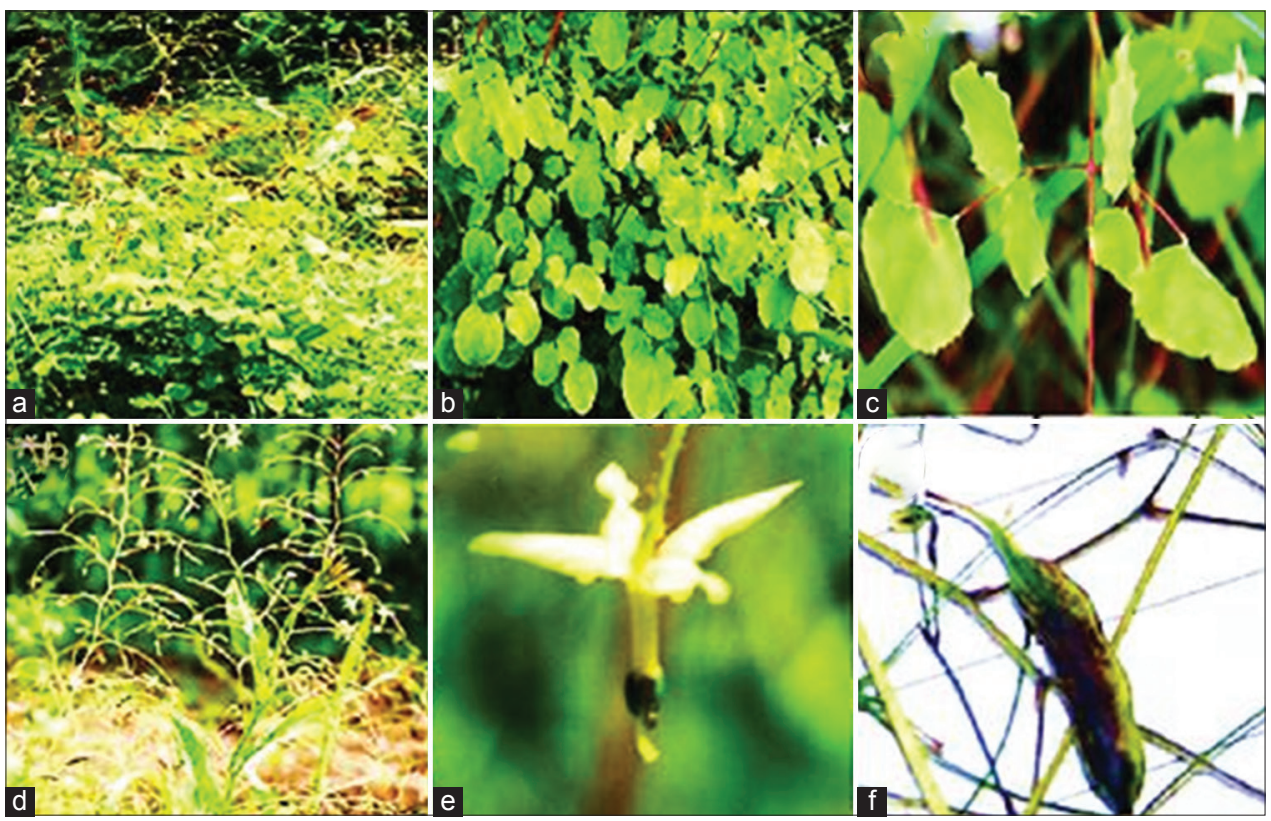

Figure 4: Morphological variability of transplanted Epimedium elatum at IIIM Yarikhah farm. (a and b) Whole plant along with inflorescence, (c) typical branch showing "three leaflets" arising from a node, (d) inflorescence with flowers and pods, (e) a typical flower, (f) pod with seeds

Table 3: Quantitative morphological parameters of E. elatum under cultivation

\begin{tabular}{lcc}
\hline Morphological parameters & \multicolumn{2}{c}{ Mean \pm SE } \\
\cline { 2 - 3 } & IIIM Srinagar farm & IIIM Yarikhah farm \\
\hline Plant height $(\mathrm{cm})$ & $42.82 \pm 3.0$ & $63.09 \pm 4.9$ \\
Leaf length & $3.73 \pm 0.32$ & $4.56 \pm 0.16$ \\
Leaf breadth & $3.13 \pm 0.04$ & $3.16 \pm 0.4$ \\
Petiole length & $1.18 \pm 0.13$ & $1.98 \pm 0.93$ \\
Internode length & $7.59 \pm 0.23$ & $10.39 \pm 1.8$ \\
No of branches/plant & $04.45 \pm 2.4$ & $60.53 \pm 11$ \\
No of leaves/branch & $9.87 \pm 0.04$ & $27.07 \pm 1.8$ \\
No of flowers/plant & $6.65 \pm 0.72$ & $160.76 \pm 20$ \\
Flower length & $1.13 \pm 0.04$ & $1.03 \pm 0.94$ \\
Flower breadth & $0.86 \pm 0.04$ & $0.89 \pm 0.00$ \\
Inflorescence length & $13.69 \pm 1.1$ & $28.53 \pm 8.54$ \\
\hline
\end{tabular}

E. elatum: Epimedium elatum, SE: Standard error

April to May whereas at high altitudes like Khillanmarg (2800-3100 m) this plant was observed to flower in the months of June-July due to altitudinal and temperature differences.

\section{Meiotic Chromosome Analysis}

In this meiotic investigation, chromosome number of E. elatum has been confirmed to be $2 \mathrm{n}=12$ including a brief outline of its meiotic behavior. At prophase I, the chromosomes and homologous pairing was prominent with apparent crossing over and chaismata formation (Figure 5a). Six discrete bivalents, linked by chaismata were visible at diplotene and diakinesis, respectively, confirming diploid chromosome number of E. elatum (Figure $5 \mathrm{~b}$ and $\mathrm{c}$ ). The bivalents were characterized by interstitial and terminal chaismata. Besides, ring-shaped bivalents were observed at diakinesis (Figure $5 \mathrm{~d}$ and e). As meiosis advanced into metaphase I, the highly condensed bivalents became aligned on the meiotic spindle and clustered in the equatorial plate of the cell (Figure $5 \mathrm{f}$ and $\mathrm{g}$ ). Some of the prominent meiotic abnormalities observed at meiosis I were interbivalent connections, multivalent formation of unoriented bivalents, chromosomal bridges, laggards (Figure 6h), chromosome stickiness (Figure $5 \mathrm{i}-\mathrm{k}$ ). Telophase I was found be normal in most of the pollen mother cells (Figure 5l). However, it is surprising to see meiotic abnormalities both in wild as well as in cultivated populations of this plant. Some of the prominent abnormalities observed during meiosis II were interbivalent connections (Figure $6 \mathrm{a}$ and $\mathrm{b}$ ) and ring bivalents (Figure $6 \mathrm{c}$ and d) at metaphase II. Anaphase II showed many abnormalities like interchromosomal connections and chromosomal connections (Figure 6e) and congested chromosomes (Figure 6f, $\mathrm{k}, \mathrm{l}$ ), interbivalent connections (Figure $6 \mathrm{~g}$ and $\mathrm{k}$ ), scattered chromosomes at three poles (Figure 6h), interbivalent connection and abnormal segregation (Figure $6 \mathrm{i}, \mathrm{j}, \mathrm{m}$ ). Telophase II is shown from Figure 6n-p with normal configuration.

\section{DISCUSSION}

Epimedium species grow on mountain cliffs under moist forests, near streams, and wet lands at altitudes ranging from 200 to $3700 \mathrm{~m}$ asl (Ying and Chen, 2001). Similar types of habitat preferences have been observed for E. elatum, an endemic monotypic taxon in Kashmir Himalayas. Endemic taxa of an area are most important because of their restricted 


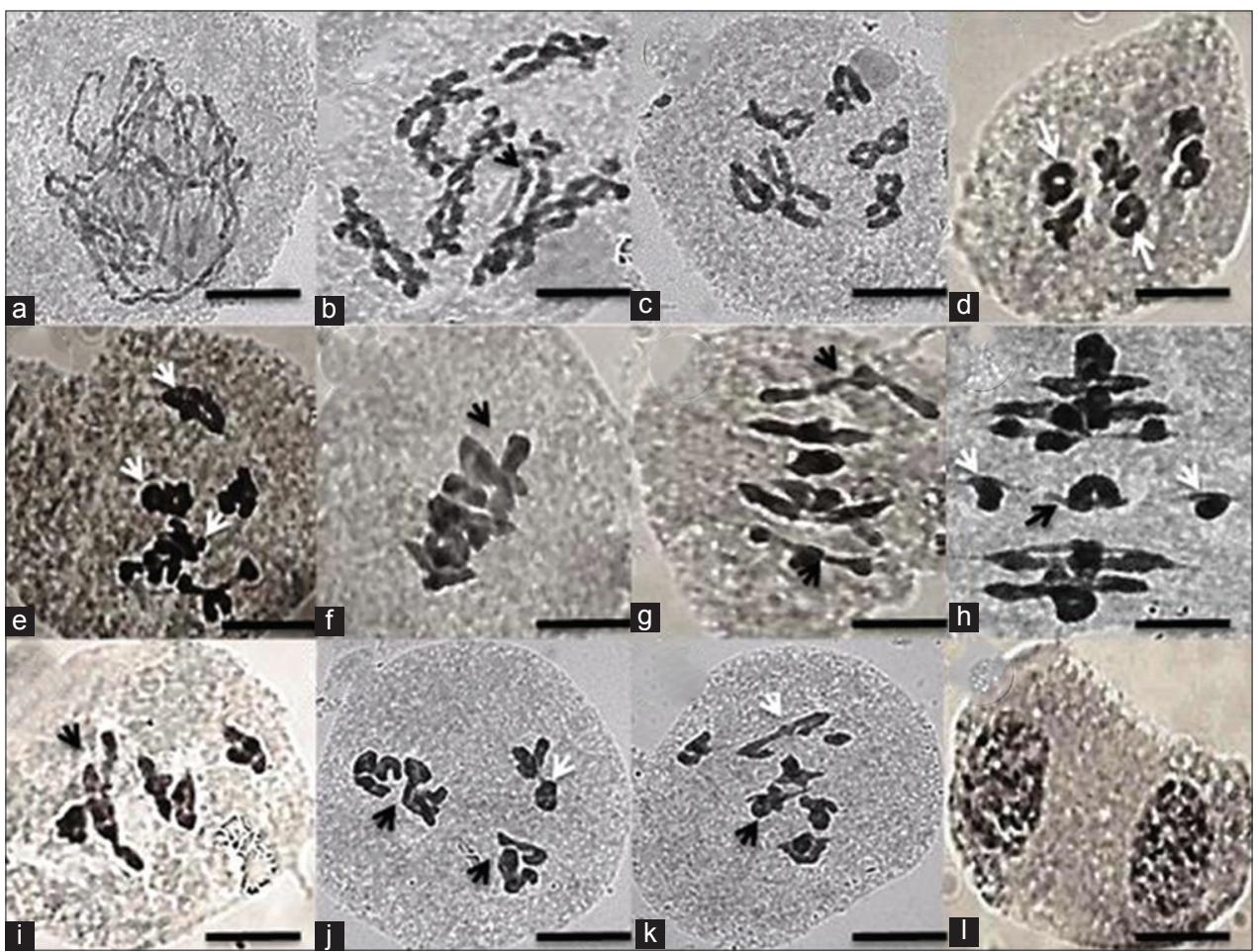

Figure 5: Different stages of meiosis I in Epimedium elatum with clear $n=6$ and $2 n=12$ chromosomes and few meiotic abnormalities. (a) Prophase I, (b and c) Diakinesis with prominent pairing, crossing over and chiasmata formation, (d) Diakinesis with sticky chromosomes and ring shaped bivalents (white arrow), (e-g) metaphase I with few abnormalities like chromatin stickiness (white arrows in E), (h) metaphase I with few univalents (white arrows), (i) metaphase I with chromatin stickiness, (j and k) metaphase I showing chromatin stickiness (white arrows) (I) telophase I (Bar-10 $\mu \mathrm{m})$

Table 4: Botanical description of E. elatum

\begin{tabular}{ll}
\hline Plant part & Botanical description of characters \\
\hline Synonyms & Epimedium hydaspidis Falc. \\
Habitat & Temperate perennial herb growing at altitudes from 1800-3300 m \\
Rootstock & Consists of perennial creeping and scaly underground rhizome with thick growth of adventitious roots \\
Stem & Glabrous, solitary, base squamate and branches are pale straw colored \\
Leaves & Ternately compound, each pinnae with 3 leaflets (three bran, petioluled, ovate-cordate, symmetrical or oblique, Terminal leaves larger \\
& than the lateral ones, subserrately toothed with spinulosus tips, submembranous, apex obtuse to rounded; petiolules shorter than the \\
& blade, thin, slightly swollen at base \\
Inflorescence & Panicle irregularly branched, glabrous to glandular-hairy \\
Flowers & Bracteates, pedicellate, complete, hermaphrodite, actinomorphic, (2) merous, hypogynous, small pale yellowish or yellowish white in \\
& color, linear-lanceolate. Floral nectaries present, Pollination entomophilous \\
& Flowering period: Early April at IIIM Srinagar and Mid-April to May at IIIM Yarikhah \\
Sepals & Fruiting period: Mid-April to May at IIIM Srinagar and Late April to May at IIIM Yarikhah \\
Petals & Polysepalous, sepals ovate-lanceolate and acute \\
Androecium & Polypetalous, petals lanceolate-elliptic with innermost honey bearing pair shorter and shoe-shaped \\
Gynoecium & Stamens 4 in number, opposite to petals. Anthers linear half as long as filaments, opening by 2 upcurved valves, crowded together \\
Fruit & Ovary simple, solitary, linear, multicarpellary (ovules 5-15), style slender, persistent, stigma dilated \\
Seed & Capsules 5-10 mm long, 2-3 mm broad, usually 2-3-seeded, submembranous, with the dorsal suture continued by a style 3-5 mm long \\
\hline
\end{tabular}

E. elatum: Epimedium elatum

distribution to a particular region and they are not found anywhere else in the world (Ali 2008). The low population size and a single distribution on a small scale might trigger their extinction. Hence, endemic species deserve immediate attention (Alam and Ali, 2010). E. elatum thus needs immediate action from conservationists, botanists, and concerned authorities involved in medicinal plant research in the Northwestern Himalayas.
The plant species showed wide morphological variation in most of the surveyed habitats. Variation in morphological characters in a species might be due to differences in ecotypes, which are often indicative of genetic differences (Clausen et al., 1948). Therefore, further various studies are needed to screen different ecotypes/chemotypes/ genotypes of this species from the Northwestern Himalayas for its early germplasm characterization and conservation. 


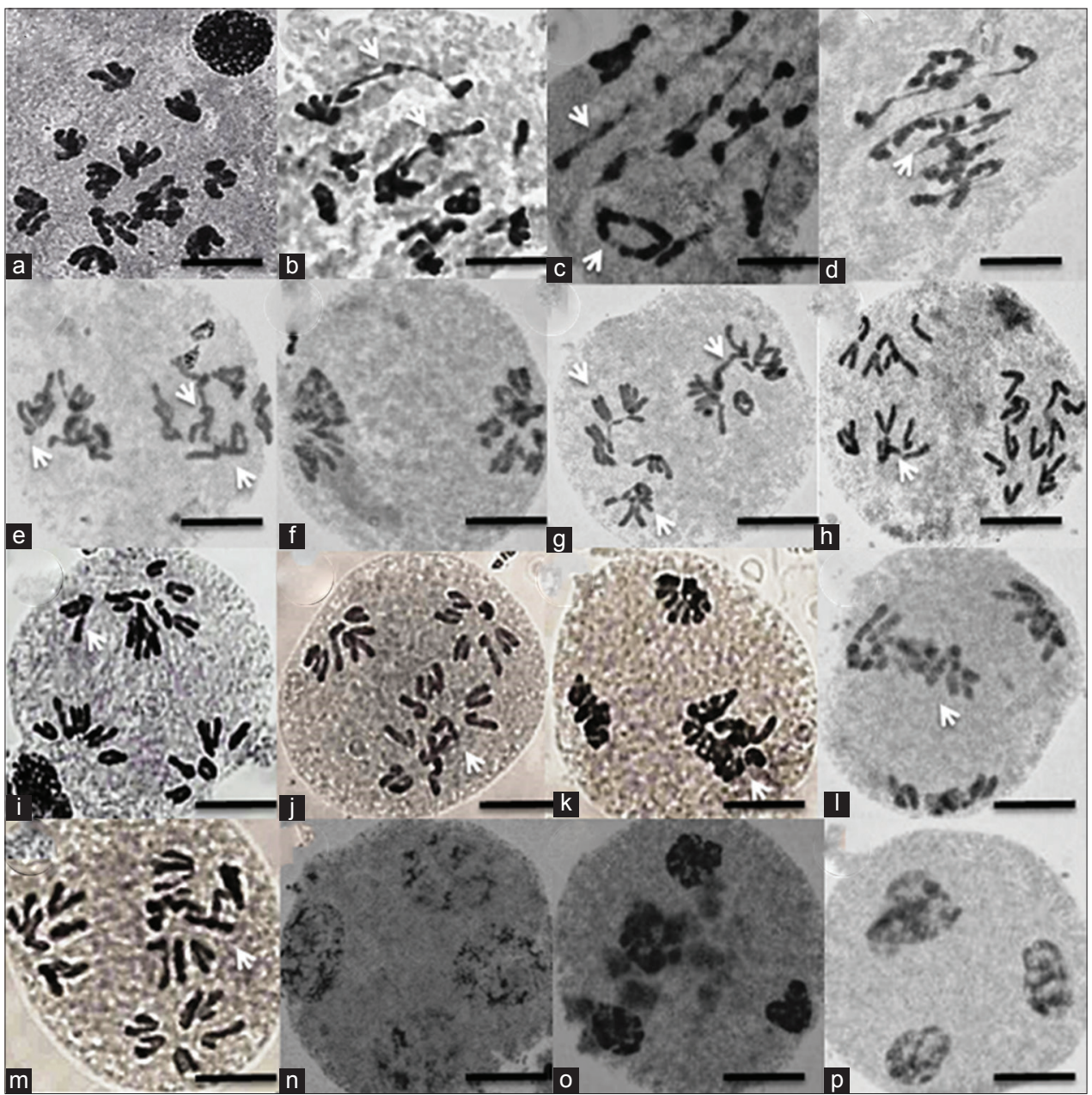

Figure 6: Various meiotic abnormalities observed during cytological characterization of Epimedium elatum. (a) Metaphase II, (b) metaphase II with interbivalent connections. (c and d) Metaphase II with ring bivalents and interbivalent connections (white arrows). (e) Anaphase I with abnormalities like interchromosomal connections (white arrows). (f) Normal anaphase I, (g) anaphase I with inter bivalent connections (white arrows). (h) Anaphase II with mixing of chromosomes at one pole. (I and j) Anaphase II. (k) Anaphase II with chromosome stickiness (I and m) anaphase II (n-p) telophase II (Bar-10 $\mu \mathrm{m})$

Phenotypic variation can enable a plant species to change its growth pattern as it encounters different stresses (Guo et al., 2007). These resulting selection pressures will vary across environmental conditions and can differently favor genotypic characters and affect phenotypic traits in different populations (Petit and Thompson., 1998). Usually, a minimum population size is required for the long-term viability of rare species and the latter occupy small geographic ranges and specific habitats (Cunningham et al., 2001; Rabinowitz, 1981; Samant et al., 1996; Mills and Schwartz., 2005; Ricketts et al., 2005). The captive cultivation of E. elatum proved successful in establishing its germplasm at high altitude medicinal garden. Shade of trees and shrubs including cool moist environment under cultivated conditions seems to be the favorable habitat for its large scale propagation. Domestication of medicinal plants is a sustainable alternative and offers the prospect to solve the problem of genetic resource erosion. Hence, by bringing E. elatum into cultivation, conventional and biotechnological techniques can be applied to improve its pharmaceutical properties for commercial purposes. Moreover, many other research activities can be conducted in future for highlighting medicinal potential of this species in Kashmir Himalayas, India.

Most of the Epimedium species have been reported to be diploid with $2 n=12$ except E.yingjiangense which is a tetraploid species with $2 n=4 \times=24$ (Sheng et al., 2010). In related cytological studies from China and Japan, chromosome numbers have been studied for 18 and 11 Epimedium species, respectively, (Sheng et al., 2010; Kuroki, 1967, 1970). The cytological studies of E. elatum confirm it as a diploid species with prominent meiotic abnormalities. Meiotic abnormalities have been previously reported in five Epimedium species from China (Jiang et al., 2011) and in few hybrid populations of this 
genus (Sheng et al., 2011). Various explanations have been given for causes of meiotic abnormalities in plants. Chromosome stickiness is observed from early prophase-I to anaphase-II, but it is more frequent during metaphase-I (Jeelani et al., 2014). It also results in the delayed separation of bivalents/chromatids at anaphase-I and II and decreases pollen viability in some species (Rao et al., 1990; Consolaro and Pagliarini., 1996). Primary cause and biochemical basis of this phenomenon are still unknown, and genetic as well as environmental factors are suggested to be the main causes (Nirmala and Rao., 1996; BaptistaGiacomelli et al., 2000). The chromatin bridges have also been noted in many PMCs and it seems to be the result of chromatin stickiness and late disjunction of bivalents. Various researchers have given their own explanations for laggards and bridge formation. Reasons given for the same phenomenon are interlocking of bivalents (Bhattacharjee, 1953), paracentric inversions (Sinha and Godward., 1972), abnormal spindle formation (Tarar and Dnyansagar, 1980) or delayed terminalization (Kumar and Tripathi, 2007). Data on pollen fertility assessment of this species could be helpful in understanding the overall effect of these abnormalities on its fruit and seed set.

\section{CONCLUSION AND CONSERVATION IMPLICATIONS}

Medicinal plants in the Northwestern Himalayas have been harvested in an unsustainable manner to meet the demand of pharmaceutical companies. The eco-geographical surveys showed that most of the habitats of E. elatum have been destroyed by human disturbance. Damage to its natural habitats would lead to a decrease in its population size and probably a subsequent increase in inbreeding, decreasing its genetic diversity. Different studies are needed for assessing exact nature of its endangerment, morphoecological behavior, reproductive biology and regional and local distribution patterns. Understanding its adaptive biology is important for development of effective agro-technology for this medicinal species. Knowledge of the adaptive mechanisms of threatened medicinal plants is crucial for both in situ and ex situ conservation and other research programs. It is also useful for attempting a largescale cultivation program to meet the bulk demand of pharmaceutical companies because growing plants within their suitable agro-climatic environment not only helps in producing higher yields but also high levels of active components (Badola and Aitken 2003). Furthermore, to avoid human over collection of medicinal plants from Kashmir Himalayas, greater awareness for protection of E. elatum must be emphasized and related research centers and forest departments should be encouraged to undertake its conservation through an integrated conservation strategy based on demographic, ecological, and genetic aspects. Extensive collection and subsequent cultivation in a shade garden and reintroduction into their original wild habitats seems feasible for E. elatum. The new environment may have important ecological differences compared with the original habitat, and the approach is technically challenging and is expensive. Therefore, ex situ conservation is recommended only to supplement in situ conservation. In vitro techniques may prove to be an effective alternative means of propagation and recovery of the rare E. elatum.

\section{ACKNOWLEDGMENTS}

The authors are thankful to director IIIM Jammu for providing necessary research facilities for carrying out the study. Acknowledgements are due to University Grants Commission (UGC), New Delhi, for providing fellowship and AcSIR cell for academic support. We are also highly thankful to Ex-HOD Botany (Dr. Irshad Nawchoo), University of Kashmir for providing facilities to carry out cytology work.

\section{REFERENCES}

Alam J, Ali SI. Contribution to the red list of the plants of Pakistan. Pak J Bot 2010;42:2967.

Ali SI. Significance of flora with special reference to Pakistan. Pak J Bot 2008:40;67-971.

Arief ZM, Munshi AH, Shawl AS. Evaluation of medicinal value of Epimedium elatum on the basis of pharmacologically active constituents, Icariin and Icariside-II. Pak J Pharm Sci 2015;28:1665-9.

Arief ZM, Shawl AS, Munshi AH. Altitudinal variation in pharmacologically active compounds of wild and cultivated populations of Epimedium elatum. J Appl Res Med Aromat Plants 2016;3:48-51.

Badola HK, Aitken S. The Himalayas of India: A treasury of medicinal plants under siege. Biodiversity 2003;4:3-13.

Baptista-Giacomelli FR, Pagliarini MS, Almeida JL. Meiotic behavior in several Brazilian oat cultivars (Avena sativa L.). Cytologia 2000;65:371-8.

Bhattacharjee SK. Cytogenetics of Lens esculenta Moench: (With Plate XIV and 11 figures). Caryologia 1953;5:159-66.

Chen J, XuY, Wei G, Liao S, ZhangY, Huang W, et al. Chemotypic and genetic diversity in Epimedium sagittatum from different geographical regions of China. Phytochemistry 2015;116:180-7.

Clausen J, Keck DD, Hiesey WM. Experimental studies on the nature of species. III. Environresponses of climatic races of Achillea. Experimental studies on the nature of species. III. 
Environresponses of climatic races of Achillea. Publication No. 581. Washington, DC: Carnegie Institution; 1948.

Consolaro ME, Pagliarini MS. Spontaneous chromosome stickiness in microsporocytes of Centella asiatica (L.) Urban (Umbelliferae). Cytologia 1996;61:57-61.

Cunningham WP, Cunningham MA, Saigo BW. Environmental Science: A Global Concern. Vol. 412. Boston, MA: McGraw-Hill; 2001.

Guo W, Li B, Zhang X, Wang R. Architectural plasticity and growth responses of Hippophae rhamnoides and Caragana intermedia seedlings to simulated water stress. J Arid Environ 2007;69:385-99.

Jeelani SM, Kumari S, Gupta RC, Siddique MA. Detailed cytomorphological investigations through male meiosis of polypetalous plants from the Kashmir Himalaya. Plant Syst Evol 2014;300:1175-98.

Jiang Y, Ding C, Yue H, Yang R. Meiotic behavior and pollen fertility of five species in the genus Epimedium. Afr J Biotechnol 2011;10:16189-92.

Kumar G, Tripathi R. Anomalous nucleolar and chromosomal organization in induced phenodeviants of grasspea. Cytologia 2007;72:345-50.

Kuroki Y. Chromosome study in four species of Berberdaceae. Memoir Ehime Uni Sec II 1970;6:215-21.

Kuroki Y. Chromosome study in seven species of Berberdaceae. Memoir Ehime Uni Sec II 1967;5:175-81.

Lone SA, Kushwaha M, Wani A, Kumar A, Gupta AP, Hassan QP, C et al. Genetic diversity, LCMS based chemical fingerprinting and antioxidant activity of Epimedium elatum Morr \& Decne. J Appl Res Med Aromat Plants 2016.

Ma H, He X, YangY, Li M, Hao D, Jia Z. The genus Epimedium: An ethnopharmacological and phytochemical review. J Ethnopharmacol 2011;134:519-41.

Mills MH, Schwartz MW. Rare plants at the extremes of distribution: Broadly and narrowly distributed rare species. Biodiv Conserv 2005;14:1401-20.

Naseer S, Lone SH, Lone JA, Khuroo MA, Bhat KA. LC-MS guided isolation, quantification and antioxidant evaluation of bioactive principles from Epimedium elatum. J Chromatogr B Analyt Technol Biomed Life Sci 2015;989:62-70.

Nasir E, Ali SI. Berberidacecace. 1980-2005 - Flora of Pakistan No. 87. Karachi: University of Karachi; 2017. p. 1-31.

Nirmala A, Rao PN. Genesis of chromosome numerical Mosaicism in higher plants. Nuc Calcutta Int J Cytol 1996:39;151-75.

Palacio-López K, Beckage B, Scheiner S, Molofsky J. The ubiquity of phenotypic plasticity in plants: A synthesis. Ecol Evol 2015;5:3389-400.

Pan J, Guo B. Effects of light intensity on the growth, photosynthetic characteristics, and flavonoid content of Epimedium pseudowushanense BL Guo. Molecules 2016:21;1475.
Perveen A, Qaiser M. Pollen flora of Pakistan-LXV. Berberidaceae. Pak J Bot 2010;42:1-6.

Petit C, Thompson JD.Phenotypic selection and population differentiation in relation to habitat heterogeneity in Arrhenatherum elatius (Poaceae). J Ecol 1998;86:829-40.

Quan QM, Fang ZL, Wu W, Li YX. Comparative analysis of morphological characteristics and effective composition content of wild and cultivated Epimedium pubescens and Epimedium wushanense (Berberidaceae). J Med Plants Res 2011;5:6523-7.

Rabinowitz D. Seven forms of rarity. In: Synge H, editor. The Biological Aspects of Rare Plant Conservation. New York: Wiley; 1981. p. 205-17.

Rao PN, Ranganadham P, Nirmala A. Behaviour of a 'sticky-desynaptic' mutant in pearl millet. Genetica 1990;81:221-7.

RickettsTH, Dinerstein E, BoucherT, BrooksTM, Butchart SH, Hoffmann M, et al. Pinpointing and preventing imminent extinctions. Proc Natl Acad Sci U S A 2005; 102:18497-501.

Samant SS, Dhar U, Rawal RS. Conservation of rare endangered plants: The context of Nanda Devi Biosphere Reserve. Conservation and Management of Biological Resources in Himalaya. New Delhi: Oxford \& IBH; 1996. p. 521-46.

Sharma BM, Jamwal PS. Flora of Upper Liddar valleys of Kashmir Himalaya. Vol. 2. Jodhpur: Scientific Publishers; 1998. p. 247.

Sheng M, Chen Q, Wang L, Tian X. Hybridization among Epimedium (Berberidaceae) species native to China. Sci Hortic 2011;128:342-51.

Sheng MY, Chen QF, Yang QX. Variation in icariin and flavonoid contents of barrenwort accessions native to Guizhou, China. Biochem Syst Ecol 2008;36:719-23.

Sheng MY, Wang LJ, Tian XJ. Karyomorphology of eighteen species of Genus Epimedium (Berberidaceae) and its phylogenetic implications. Genet Resour Crop Evol 2010;57:1165-76.

Singh G, Kachroo P. Forest Flora of Srinagar and Plants of Neighbourhood. Delhi: Periodical Expert Book Agency; 1987. p. 278.

Sinha SS, Godward MB. Radiation studies in Lens culinaris meiosis: Abnormalities induced due to gamma radiation and its consequences. Cytologia 1972;37:685-95.

Sofi SN, Shakeel-U-Rehman, Qazi PH, Lone SH, Bhat HM, Bhat KA.I solation, identification, and simultaneous quantification of five major flavonoids in Epimedium elatum by high performance liquid chromatography. J Liq Chromatogr Relat Technol 2014;37:1104-13.

Tali BA, Ganie AH, Nawchoo IA, Wani AA, Reshi ZA. Assessment of threat status of selected endemic medicinal plants using IUCN regional guidelines: A case study from Kashmir Himalaya. J Nat Conserv 2015;23:80-99.

Tantry MA, Dar JA, Idris A, Akbar S, Shawl AS. Acylated 
flavonol glycosides from Epimedium elatum, a plant endemic to the Western Himalayas. Fitoterapia 2012;83:665-70.

Tarar JL, DnyansagarVR. Comparison of ethyl methanesulfonate and radiation induced meiotic abnormalities in Turnera ulmifolia Linn. var. Angustifolia willd. Cytologia 1980;45:221-31.

The Plant List. Version 1.1. Published on the Internet; 2013. Available from: http://www.theplantlist.org/. [Last accessed on 2017 Jan 01].

XuYQ, CaiWZ, Hu SF, Huang XH, Ge F, WangY. Morphological variation of non-glandular hairs in cultivated Epimedium sagittatum (Berberidaceae) populations and implications for taxonomy. Biodiv Sci 2013;21:185-96.
Xu YQ, Xu Y, Shi HJ, Hu SF, Ge F. Taxonomic research on Epimedium sagittatum species complex and discussion. Chin Tradit Herb Drugs 2014;22:029.

Xuemei Z, Zengli F, Qiumei Q. Impact of simulated warming on growthand floral characteristics of two varieties of medicinal Epimedium. Braz Arch Biol Technol 2016;59:e16160546.

Ying JS, Chen DZ. Republican Popularize Sinicae. Vol. 29. Beijing: Science Press; 2001. p. 272.

Zhang Y, Du L, Liu A, Chen J, Wu L, Hu W, et al. The complete chloroplast genome sequences of five Epimedium species: Lights into phylogenetic and taxonomic analyses. Front Plant Sci 2016;7:306. 